\title{
Postface: Editors's Note
}

Insect Science and Its Application has been undergoing a major reorganisation of both its management and editorial policy. In an effort to put the journal back onto a timely publication schedule, we have been processing the backlog of manuscripts accepted for publication as soon as they have been reviewed, edited and revised according to our new policies. In this Volume, therefore, manuscripts accepted in 1999 may be antedated and published in Volume $18 \mathrm{Number} 4$ (1998). A slightly revised Instructions to Authors appears in this issue, and will continue to be amended from time to time to reflect changes in our procedures.

A. Ng'eny Mengech Coordinating Editor 